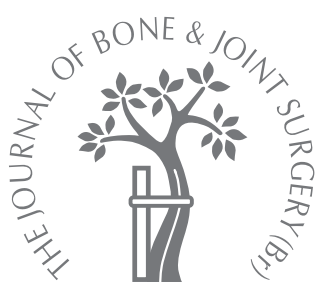

A. B. Pedersen,

J. A. Baron,

S. Overgaard,

S. P. Johnsen

From the Department

of Clinical

Epidemiology,

Aarhus University

Hospital, Aarhus,

Denmark
A. B. Pedersen, MD, PhD, Staff Specialist, Post-doctoral

Fellow

S. P. Johnsen, MD, PhD,

Associate Professor

Department of Clinical

Epidemiology

Aarhus University Hospital,

Olof Palmes Alle 43-45, 8200

Aarhus N, Denmark.

J. A. Baron, MD, MSc

Professor

Departments of Medicine and

Community and Family

Medicine, Section of

Biostatistics and Epidemiology

Dartmouth Medical School, 1

Medical Centre Drive, 8th Floor

Rubin Lebanon, New

Hampshire 03755, USA

S. Overgaard, MD, DMSc,

Professor

Department of Orthopaedic

Surgery

Odense University Hospital,

Sdr. Boulevard 29, 5000

Odense, Denmark.

Correspondence should be sent to $\operatorname{Dr}$ A. B. Pedersen; e-mail:

abp@dce.au.dk

(C)2011 British Editorial Society of Bone and Joint Surgery doi:10.1302/0301-620X.93B2.

$25629 \$ 2.00$

$J$ Bone Joint Surg [Br]

2011;93-B:172-7.

Received 28 July 2010;

Accepted 23 September 2010

\title{
Short- and long-term mortality following primary total hip replacement for osteoarthritis
}

\author{
A DANISH NATIONWIDE EPIDEMIOLOGICAL STUDY
}

We evaluated the short-term of $\mathbf{0}$ to $\mathbf{9 0}$ days and the longer term, up to $\mathbf{1 2 . 7}$ years, mortality for patients undergoing primary total hip replacement (THR) in Denmark in comparison to the general population. Through the Danish Hip Arthroplasty Registry we identified all primary THRs undertaken for osteoarthritis between 1 January 1995 and 31 December 2006. Each patient ( $n=44558$ ) was matched at the time of surgery with three people from the general population ( $n=133674$ ). We estimated mortality rates and mortality rate ratios with 95\% confidence intervals for THR patients compared with the general population. There was a one-month period of increased mortality immediately after surgery among THR patients, but overall short-term mortality ( 0 to 90 days) was significantly lower (mortality rate ratio $0.8 ; 95 \%$ confidence interval 0.7 to 0.9 ). However, THR surgery was associated with increased short-term mortality in subjects under 60 years old, and among THR patients without comorbidity. Long-term mortality was lower among THR patients than in controls (mortality rate ratio $0.7 ; 95 \%$ confidence interval 0.7 to 0.7 ).

Overall, THR was associated with lower short- and long-term mortality among patients with osteoarthritis. Younger patients and patients without comorbidity before surgery may also experience increased mortality after THR surgery, although the absolute risk of death is small.

Total hip replacement (THR) is widely considered to be cost-effective and safe. ${ }^{1,2}$ However, only a few studies have reported mortality following primary THR in a population-based sample and made comparisons with the corresponding general population. Mortality has been reported to be higher for THR patients than that of the corresponding population in the first 30 days after surgery, but variously similar or lower mortality has been reported for the period between 60 and 90 days. ${ }^{3-5}$ Long-term mortality has been reported to be lower than that of controls. ${ }^{4}$

Comorbidity is a well-established prognostic factor for many diseases as well as for adverse outcomes after medical interventions. ${ }^{6-8}$ The available literature on the impact of comorbidity on short- and long-term mortality among THR patients is limited. ${ }^{3,9-13}$ It is well accepted that THR is recommended for patients with little or no comorbidity, as adverse outcomes increase as the number of comorbid conditions rises. ${ }^{5}$ One study examined the impact of age and gender on shortand long-term mortality among THR patients relative to the controls from the general popu- lation. ${ }^{4}$ It was observed that there was an increase in long-term mortality with decreasing age at operation, but this pattern could not be confirmed for short-term mortality. An important question is how much THR surgery affects mortality in selected healthy and young patients compared with corresponding controls who have not required THR, both in the short and the long term.

Vascular disease has been reported as the most common cause of death among THR patients in general during the first 60 and 90 days post-operatively, and for up to four years after surgery. ${ }^{9-11}$ However, cause-specific mortality among THR patients has not been well studied. In order to clarify these issues, we conducted a nationwide, population-based study on the short- and long-term mortality among THR patients with osteoarthritis in relation to age, gender and comorbid conditions before surgery.

\section{Patients and Methods}

Data sources. We used medical databases in Denmark to identify patients who have undergone THR and to ascertain their status during 
the subsequent years. The Danish Hip Arthroplasty Registry ${ }^{14}$ holds data on all patients with a primary or revision THR performed in Denmark since 1 January 1995. All 45 orthopaedic departments in Denmark, including five private hospitals, report to the registry. Pre-, peri- and postoperative data are collected by the operating surgeon using a standardised form. The Danish Civil Registration System is a national registry of all Danish residents which has maintained records regarding status and residence for the entire population since 1968. The Danish National Registry of Patients has kept data on all acute care hospital admissions since 1977 (and since 1995, for all hospital specialist outpatient visits), including the dates of admission and discharge, and up to 20 discharge diagnoses classified according to the International Classification of Diseases ${ }^{15}$ (Eighth edition until the end of 1993, Tenth edition thereafter). The Danish Registry of Causes of Death has kept information on causes of death on all Danish citizens who have died since 1970. A death certificate must be filed for every person who dies; it is completed by the physician with the most accurate knowledge of the events that led to death. Causes of death are coded according to the International Classification of Diseases (Tenth edition) as the underlying cause of death and up to three additional immediate causes. All Danish citizens are assigned at birth a unique ten-digit personal identification number encoding age, gender and date of birth. This permits unambiguous linkage between all Danish medical databases. ${ }^{16}$

Study population. Using the Danish hip registry, we identified all primary THR patients with osteoarthritis operated on during the period between 1 January 1995 and 31 December 2006. Only the initial THR recorded in the registry was included. There were 44558 patients in the final study population.

Each THR patient was matched by year of birth and gender at the time of surgery with three people from the general population who were alive on the date of that patient's surgery, irrespective of their previous THR history. These controls were randomly sampled using the Danish Civil Registration system. Sampling was with replacement, so an individual could be chosen as a control more than once. In all, 4663 persons were chosen as a control twice, 137 were chosen three times, and four people were chosen four times for different THR patients. Thus 133674 age- and gendermatched controls from the general population were included in the final study population.

Comorbidity. For each THR patient and control, we identified all primary and secondary discharge diagnoses for all hospital admissions since 1977, and hospital specialist outpatient visits since 1995 prior to the time of surgery. Using these data, we computed the Charlson comorbidity index score. ${ }^{7,17}$ This index, originally developed and validated for the prediction of short- and long-term mortality in patients admitted to departments of internal medicine, ${ }^{17}$ includes 19 major disease categories, including cardiovascular, cerebrovascular, chronic pulmonary, liver, renal and gastro- intestinal diseases, diabetes, and solid and haematological tumours. Admissions from each category are weighted as one, two, three or six points, and the score is the sum of these weightings. We classified the patients and controls according to three levels of comorbidity: low (those with a score of zero prior to the time of surgery or index date); moderate (those with one or two points); and a high index (those with more than two points). ${ }^{18}$

Apart from studying the effect of three different categories of Charlson comorbidity index on the association between THR and mortality, we aimed to study the prognostic effect of specific comorbidities. We therefore also classified the THR patients and controls according to their prior hospital admission with cardiovascular diseases (myocardial infarction, congestive heart failure, peripheral vascular disease and/or cerebrovascular disease), diabetes and cancer.

Mortality. The outcomes studied were short-term mortality, within 90 days after surgery, and subsequent longer-term mortality. All subjects were followed until 16 September 2007, when the information on vital status and cause of death was obtained. The following causes of death were examined: myocardial infarction, congestive heart failure, venous thromboembolism, pneumonia, stroke, upper gastrointestinal ulcers and any cancer. Both THR patients and controls could have multiple causes of death on the death certificate.

Statistical analysis. We computed all-cause mortality rates as the number of deaths within a specific subject category divided by the number of person-years at risk within the same group of subjects, expressed per 100 000. Mortality rates were calculated separately for THR patients and controls within groups defined by gender, age in the ranges ten to 59,60 to 69,70 to 79 and $>80$ years. The Charlson comorbidity index was calculated using the categories listed above and their specific comorbid diagnoses (cardiovascular diseases, diabetes and cancer). We used Cox's proportional hazards regression to estimate all-cause and cause-specific mortality rate ratios and $95 \%$ confidence intervals (CI), both crude and adjusted for gender, age and Charlson comorbidity index. As our preliminary analyses indicated that the mortality rate ratios, adjusted for the 19 diagnoses included in the Charlson index, were similar to those adjusted for the Charlson comorbidity index, we presented estimates adjusted for the Charlson index. Analyses were conducted for short-term mortality (0 to 90 days) and long-term mortality (subsequent follow-up). We used likelihood-ratio tests to test for heterogeneity. Additional analyses were carried out to examine the attributable risk by subtracting the mortality in the general population from that in the THR patients.

Our preliminary analyses indicated that the mortality rate ratios stratified by matched THR patient-control sets from the background population did not differ from those that were the result of the Cox model without stratification. Therefore, all presented estimates were derived from the unstratified Cox's proportional hazards model. Log-log plots $^{19}$ and Schoenfeld residuals ${ }^{20}$ did not indicate deviation from the 
Table I. Characteristics of patients with osteoarthritis who underwent total hip replacement (THR) and controls from the general population

\begin{tabular}{|c|c|c|}
\hline & THR patients ( $n=44558$ ) (\%) & $\begin{array}{l}\text { Population controls } \\
(\mathrm{n}=133674)(\%)\end{array}$ \\
\hline \multicolumn{3}{|l|}{ Gender } \\
\hline Female & $25036(56)$ & $75108(56)$ \\
\hline Male & 19522 & 58566 \\
\hline \multicolumn{3}{|l|}{ Age (years) } \\
\hline 10 to 59 & $7665(17)$ & $23082(17)$ \\
\hline 60 to 69 & $14218(32)$ & $42590(32)$ \\
\hline 70 to 79 & $16264(36)$ & $48778(36)$ \\
\hline More than 80 & $6411(14)$ & $19224(14)$ \\
\hline \multicolumn{3}{|l|}{ Charlson comorbidity index } \\
\hline Low & 30201 (68) & $87994(66)$ \\
\hline Moderate & $11756(26)$ & $35812(27)$ \\
\hline High & $2601(6)$ & $9868(7)$ \\
\hline \multicolumn{3}{|l|}{ Previous hospital admissions } \\
\hline Cardiovascular diseases & $6023(13)$ & $21529(16)$ \\
\hline Diabetes & $1561(3)$ & $5817(4)$ \\
\hline Any cancer & $4022(9)$ & $12812(10)$ \\
\hline $\begin{array}{l}\text { Hospitalisation with any of the } 19 \text { diagnoses included in } \\
\text { the Charlson comorbidity index }\end{array}$ & $14357(32)$ & $45680(34)$ \\
\hline $\begin{array}{l}\text { Hospitalisation with any of the } 19 \text { diagnoses included in } \\
\text { the Charlson comorbidity index, except for musculoskeletal } \\
\text { diseases }\end{array}$ & $13442(30)$ & 43678 (33) \\
\hline
\end{tabular}

assumption of proportional hazards. All analyses were performed using the Stata Statistical Software: Release 9.0 (Stata Corp., College Station, Texas), and p-values $<0.05$ were taken to denote statistical significance.

The study was approved by the Danish Data Protection Agency.

\section{Results}

Study population. THR patients with osteoarthritis had slightly fewer comorbid conditions on previous hospital admissions than did controls; the proportion with one or more non-musculoskeletal comorbid diagnoses at the time of surgery was $30 \%$ in THR patients versus $33 \%$ in controls ( $p$ $<0.001$ ). Including musculoskeletal diagnoses, the proportions were $32 \%$ vs $34 \%(\mathrm{p}<0.001)$ (Table I). However, this pattern varied according to age and gender, being more pronounced for subjects $>60$ years and for women. In contrast, among subjects $<60$ years old the proportion of non-musculoskeletal comorbid diagnoses was $17 \%$ vs $16 \%$ for THR patients and controls, respectively $(\mathrm{p}<0.001)$, and the proportions with any comorbid diagnoses were $19 \%$ and $17 \%$, respectively $(\mathrm{p}<0.001)$. THR patients had a lower prevalence of previous cardiovascular and chronic pulmonary disease, as well as diabetes, than controls. However, younger THR patients had a slightly higher prevalence of these diseases, in addition to inflammatory diseases, than controls.

Short-term mortality following THR ( 0 to 90 days). Overall short-term (90-day) mortality among THR patients with osteoarthritis was low, lower than among matched controls (mortality rate 7.5 (95\% CI 6.7 to 8.4 ) vs 10.2 (95\% CI 9.6 to 10.8 ) per $100000, \mathrm{p}<0.001)$, corresponding to an adjusted mortality rate ratio of $0.8(95 \%$ CI 0.7 to 0.9$)$ and a negative attributable risk of 2.7 per 100000 person- years. However, in the 30 days after surgery, mortality was higher among THR patients (adjusted mortality rate ratio $1.4(95 \%$ CI 1.2 to 1.7$))$, decreasing thereafter so that the cumulative mortality at 60 days was identical to that in controls (adjusted mortality rate ratio of 1.0 (95\% CI 0.9 to 1.1$))$ and subsequently became lower.

The relative mortality varied according to gender, age and comorbidity. The reduction in overall 90-day mortality among THR patients with osteoarthritis was confined to women (adjusted all-cause mortality rate ratio 0.6 (95\% CI 0.5 to 0.8$)$ ); for men, short-term mortality was identical among THR patients and controls $(\mathrm{p}<0.001)$ (Table II). The mortality rates at 90 days were lower for THR patients than for controls for all the age categories except for the youngest THR patients, and the absolute difference in rates increased with age. THR patients $<60$ years with osteoarthritis had an increased relative all-cause mortality within 90 days (adjusted mortality rate ratio $=2.1,95 \%$ CI 1.1 to 3.7), which was in clear contrast to subjects $>60$ years $(\mathrm{p}<0.001)$ (Table II). The same pattern was observed for the 30-day and 60-day mortality, with the adjusted mortality rate ratio for THR patients $<60$ years being 5.5 (95\% CI 2.2 to 15.6$)$ and 2.7 (95\% CI 1.4 to 5.5), respectively, compared with controls of the same age. The increase in relative mortality among patients $<60$ years was independent of comorbidity index.

The reduced 90-day mortality for THR patients was also confined to individuals with a moderate or high Charlson comorbidity index, in contrast to subjects with a low index, who had a similar risk to those in the general population $(p<0.001)$ (Table II). The adjusted relative mortality by 30 days and 60 days after surgery in those without prior comorbidity was 2.1 (95\% CI 1.5 to 2.9$)$ and 1.4 (95\% CI 
Table II. Mortality rates and mortality rate ratios (MRR) of total hip replacement (THR) patients operated on for osteoarthritis versus age- and gendermatched controls from the general population

\begin{tabular}{|c|c|c|c|c|c|c|c|c|}
\hline & \multicolumn{4}{|l|}{0 to 90 days } & \multicolumn{4}{|c|}{90 days to 12.7 years } \\
\hline & $\begin{array}{l}\text { Mortality rates } \\
\text { THR vs general } \\
\text { population }\end{array}$ & $\begin{array}{l}\text { THR, } \\
\text { number } \\
\text { deaths/N }\end{array}$ & $\begin{array}{l}\text { General } \\
\text { population, } \\
\text { number } \\
\text { deaths/N }\end{array}$ & $\begin{array}{l}\text { Adjusted MRR } \\
(95 \% \mathrm{Cl})\end{array}$ & $\begin{array}{l}\text { Mortality rates* } \\
\text { THR vs general } \\
\text { population }\end{array}$ & $\begin{array}{l}\text { THR, } \\
\text { number } \\
\text { deaths/N }\end{array}$ & $\begin{array}{l}\text { General } \\
\text { population, } \\
\text { number deaths/N }\end{array}$ & $\begin{array}{l}\text { Adjusted } \\
\text { MRR }^{\dagger} \\
(95 \% \mathrm{Cl})\end{array}$ \\
\hline \multicolumn{9}{|l|}{ Gender } \\
\hline Female & 5.6 vs 9.8 & $127 / 25036$ & $658 / 75108$ & $0.6(0.5$ to 0.8$)$ & 8.5 vs 11.7 & $4080 / 24909$ & $15957 / 74449$ & $0.7(0.7$ to 0.7$)$ \\
\hline Male & 9.8 vs 10.8 & $171 / 19522$ & $565 / 58566$ & $1.0(0.8$ to 1.2$)$ & 10.1 vs 13.5 & $3651 / 19351$ & $13863 / 58001$ & $0.7(0.7$ to 0.7$)$ \\
\hline \multicolumn{9}{|l|}{ Age (years) } \\
\hline 10 to 59 & 2.8 vs 1.3 & $19 / 7665$ & $27 / 23082$ & 2.1 (1.1 to 3.7$)$ & 2.3 vs 2.4 & $361 / 7646$ & $1120 / 23055$ & $0.9(0.8$ to 1.1$)$ \\
\hline 60 to 69 & 3.0 vs 4.8 & $38 / 14218$ & $185 / 42590$ & $0.6(0.4$ to 0.9$)$ & 5.0 vs 6.8 & $1400 / 14180$ & $5500 / 42404$ & 0.7 (0.7 to 0.8 ) \\
\hline 70 to 79 & 8.6 vs 11.8 & $125 / 16264$ & $514 / 48778$ & $0.8(0.6$ to 0.9$)$ & 11.8 vs 16.1 & $3614 / 16139$ & $13825 / 48264$ & $0.7(0.7$ to 0.8$)$ \\
\hline$\geq 80$ & 20.4 vs 29.1 & $116 / 6411$ & $497 / 19224$ & $0.8(0.7$ to 1.0$)$ & 22.8 vs 35.9 & $2356 / 6295$ & $9375 / 18726$ & $0.6(0.6$ to 0.7$)$ \\
\hline \multicolumn{9}{|c|}{ Charlson comorbidity index } \\
\hline Low & 4.3 vs 3.9 & 118/30 201 & 309/87 994 & $1.1(0.9$ to 1.3$)$ & 6.9 vs 8.2 & $4184 / 30083$ & $14083 / 87683$ & $0.8(0.7$ to 0.8$)$ \\
\hline Moderate & 12.9 vs 15.7 & 135/11 756 & $503 / 35812$ & $0.8(0.7$ to 1.0$)$ & 13.7 vs 20.2 & $2725 / 11621$ & $11282 / 35309$ & 0.7 (0.6 to 0.7$)$ \\
\hline High & 19.4 vs 47.2 & $45 / 2601$ & $411 / 9868$ & $0.4(0.3$ to 0.6$)$ & 23.1 vs 40.6 & $822 / 2556$ & $4455 / 9457$ & $0.6(0.5$ to 0.6$)$ \\
\hline \multicolumn{9}{|c|}{ Previous hospitalisations } \\
\hline Cardiovascular & 20.9 vs 27.0 & $112 / 6023$ & $517 / 21529$ & $0.8(0.7$ to 1.0$)$ & 17.8 vs 28.5 & $1661 / 5911$ & $8454 / 21012$ & $0.6(0.6$ to 0.7$)$ \\
\hline Diabetes & 18.7 vs 25.1 & $26 / 1561$ & $130 / 5817$ & $0.8(0.5$ to 1.2$)$ & 17.0 vs 27.0 & $391 / 1535$ & $2107 / 5687$ & $0.6(0.6$ to 0.7$)$ \\
\hline Any cancer & 10.8 vs 32.1 & $39 / 4022$ & $365 / 12812$ & $0.3(0.2$ to 0.5$)$ & 16.1 vs 24.7 & $1050 / 3983$ & $4413 / 12447$ & $0.6(0.6$ to 0.7$)$ \\
\hline
\end{tabular}

* per 100000 person-years

† MRR, adjusted for gender, age and Charlson comorbidity index. As the MRRs adjusted for 19 diagnoses included in the Charlson index were similar to MRRs adjusted for Charlson comorbidity index as such, we present estimates adjusted for Charlson index. All comparisons were between cases and controls with the same characteristics, i.e. THR with diabetes before surgery were compared with controls with diabetes before surgery. $\mathrm{N}$, number of subjects; Cl, confidence intervals.

1.1 to 1.7$)$, respectively, for THR patients compared with controls also without comorbidities.

Long-term mortality following THR (90 days to 12.7 years). During the maximum follow-up of 12.7 years, 94410 subjects were followed for no more than five years, 64435 for five to ten years, and 19386 for ten years or more. In the long term, THR patients with osteoarthritis had a lower mortality than population controls. Thus, a total of 7731 $(17.5 \%)$ THR patients with osteoarthritis died during follow-up after 90 days (mortality rate 9.2 (95\% CI 9.0 to 9.4) per 100000 person-years), as did 29820 (22.5\%) controls (mortality rate 12.4 (95\% CI 12.4 to 12.7 ) per 100000 person-years). The adjusted mortality rate ratio was 0.7 (95\% CI 0.7 to 0.7 ) and the attributable risk was reduced by 3.2 per 100000 person-years. The lower relative mortality was seen in all subgroups, with the exception of individuals $<60$ years, among whom THR patients had a similar longterm mortality as controls (mortality rate ratio $=0.9,95 \%$ CI 0.8 to 1.1 ) (Table II). Again, the mortality rates were lower for THR patients than for controls in all age groups, and the absolute differences increased with age.

Cause-specific mortality. THR patients with osteoarthritis had increased 90-day mortality from myocardial infarction and venous thromboembolism/pulmonary embolism than matched controls, irrespective of age, gender and prior comorbidity index (Table III). In contrast, short-term cancer mortality was lower (adjusted mortality rate ratio was 0.2 (95\% CI 0.1 to 0.3$))$. THR patients with osteoarthritis had decreased long-term mortality due to all specific causes of death examined in our study (Table III), even after adjustment for age, gender and comorbidity index.

\section{Discussion}

In this nationwide population-based cohort study we found that THR in patients with osteoarthritis was associated with lower short- and long-term mortality than in matched controls. However, there was an increased short-term mortality risk confined to younger patients ( $<60$ years old) and to subjects without prior comorbidity noted on previous hospital admissions and specialist outpatient visits. Patients undergoing THR had an increased 90-day risk of death from myocardial infarction and deep venous thrombosis/pulmonary embolism, irrespective of age, gender and comorbidity index.

Mortality among THR patients has previously been compared with that of the general population. ${ }^{3-5}$ Our findings that overall mortality within 60 days of THR in patients with osteoarthritis was about equal to that in the underlying population, conflict with results reported by Lie et $\mathrm{al},{ }^{4}$ who observed a $41 \%$ lower mortality. Possible explanations for the differences are the selection of patients for primary THR or differences in the definition of a diagnosis of osteoarthritis between Denmark and Norway. Both our study and that of Barrett et $\mathrm{al}^{3}$ found that within 30 days of surgery mortality among THR patients was increased, with a subsequent decline in relative mortality over time. Lie et $\mathrm{al}^{21}$ recently reported a small increase in mortality within 26 days post-operatively. In contrast to our findings, Mahomed et $\mathrm{al}^{5}$ and Barrett et $\mathrm{al}^{3}$ reported that the probability of dying did not differ between THR patients and matched controls over the 90-day period after surgery. However, these studies included both patients with osteoarthritis and those with rheumatoid arthritis, making comparisons difficult. 
Table III. Cause-specific 90-day mortality rate ratios (MRRs) with 95\% confidence interval (CI) among total hip replacement (THR) patients with osteoarthritis compared with controls from the general population

\begin{tabular}{|c|c|c|c|c|}
\hline \multirow[b]{3}{*}{$\begin{array}{l}\text { Cause of death according to International } \\
\text { Classification of Disease, Tenth edition } \\
(\text { ICD-10) }\end{array}$} & \multicolumn{4}{|c|}{ Osteoarthritis, THR versus general population } \\
\hline & \multicolumn{2}{|l|}{0 to 90 days } & \multicolumn{2}{|l|}{90 days to 12.7 years } \\
\hline & $\begin{array}{l}\text { Number of deaths } \\
(\%)^{\dagger}\end{array}$ & $\begin{array}{l}\text { Adjusted MRR } \\
\left(95 \% \mathrm{Cl}^{\ddagger}\right)\end{array}$ & Number of deaths $(\%)^{\dagger}$ & $\begin{array}{l}\text { Adjusted } \mathrm{MRR}^{\ddagger} \\
(95 \% \mathrm{Cl})\end{array}$ \\
\hline $\begin{array}{l}\text { Myocardial infarction } \\
\text { (I21.0 to I21.9, I23) }\end{array}$ & $64(21) / 85(7)$ & $2.1(1.5$ to 2.9$)$ & $6416(8) / 2093167$ (7) & $0.8(0.8$ to 0.9$)$ \\
\hline $\begin{array}{l}\text { Congestive heart failure } \\
(|11.0,| 13.0, \mid 13.2,150.0 \text { to } 150.3,150.8)\end{array}$ & $22(7) / 78(6)$ & $0.9(0.9$ to 1.5$)$ & $5689(7) / 209152(7)$ & $0.7(0.7$ to 0.8$)$ \\
\hline $\begin{array}{l}\text { Deep venous thrombosis/pulmonary } \\
\text { embolism } \\
(126,180.1 \text { to } 180.9,182.1 \text { to } 182.9)\end{array}$ & $31(10) / 17(1)$ & 5.7 (3.2 to 10.3$)$ & $122(2) / 443(2)$ & $0.8(0.6$ to 0.9$)$ \\
\hline $\begin{array}{l}\text { Stroke } \\
\text { (I60 to } 169, \mathrm{G} 45, \mathrm{G} 46)\end{array}$ & $31(10) / 123(10)$ & $0.8(0.6$ to 1.2$)$ & $775(10) / 3002(10)$ & $0.7(0.6$ to 0.8$)$ \\
\hline $\begin{array}{l}\text { Pneumonia } \\
\text { (J12.x to J18.x, A481, A709) }\end{array}$ & $29(10) / 130(11)$ & $0.8(0.5$ to 1.1$)$ & $826(11) / 3474(12)$ & $0.6(0.6$ to 0.7$)$ \\
\hline $\begin{array}{l}\text { Upper gastrointestinal ulcer } \\
\text { (K22.1, K25 to K28) }\end{array}$ & $13(4) / 23(2)$ & $1.7(0.9$ to 3.4$)$ & $119(2) / 394(1)$ & $0.8(0.7$ to 1.0$)$ \\
\hline $\begin{array}{l}\text { Any cancer } \\
\text { (C00 to C85, C91 to C95, C88, C90, C96) }\end{array}$ & $19(6) / 288(24)$ & 0.2 (0.1 to 0.3$)$ & $2110(27) / 6792(23)$ & $0.9(0.8$ to 0.9$)$ \\
\hline
\end{tabular}

As in our data, an increased long-term relative mortality after THR in patients younger than 60 years of age has been reported by Ramiah et $\mathrm{al}^{22}$ and Lie et al. ${ }^{4}$ Our data further suggest increased short-term relative mortality among younger THR patients with osteoarthritis and those without previous hospital admissions, indicating that although THR is a low-risk procedure, it still imposes a risk that becomes most evident in patients with a low baseline mortality risk. The increased relative risk among patients who are young or with a good pre-operative prognostic profile may reflect patient-related factors such as obesity, which may be associated with both the development of osteoarthritis at a young age and an increased procedurerelated risk of adverse outcome, including death, as well as system-related factors which might include a lower level of awareness by health professionals towards the prevention, detection and treatment of thromboembolic complications in patients considered to have a low risk. Another possible explanation may be the fact that any surgical procedure carries a risk which, added to a small baseline risk in these patients, results in a high relative mortality. It is also possible that the risk may not be offset by selection among these low-risk patients, as it may be among those that are high risk. Although the relative risk was highest for younger patients, it is important to notice that the absolute mortality risk was small among these patients.

The mortality for THR patients may be put into clinical perspective by comparison with mortality among patients undergoing elective inguinal hernia repair $^{23}$ or cataract extraction. ${ }^{24}$ Both procedures carry an absolute mortality risk that is lower than that among THR patients, probably owing to the shorter duration of surgery. Nevertheless, the relative risk of dying compared with that of subjects not undergoing these procedures is increased for the youngest age groups, and decreased afterwards.

Our finding that THR is associated with increased relative short-term mortality due to myocardial infarction and venous thromboembolism/pulmonary embolism agrees with previous observations ${ }^{10,12,25}$ and was independent of age and level of comorbidity before the surgery. This strongly indicates that the prevention and treatment of thromboembolic events should play a central role when aiming to reduce or eliminate avoidable deaths following THR. There is no doubt that target patients should be those at the highest absolute risk of mortality. Nevertheless, given the current growth in the number of procedures performed in young healthy patients, ${ }^{26}$ as well as the constant broadening of the indication for THR due to increasing expectations for quality of life, ${ }^{27}$ more attention needs to be paid to identifying clinically and financially efficient strategies for preventing adverse outcomes, including death, following routine THR among patients with the highest relative risk.

The lower short-term mortality observed among THR patients with osteoarthritis compared with matched controls with similar moderate and high comorbidity is likely to be explained by the careful selection of patients for surgery. This selection bias is presumably reflected further in the reduced long-term mortality among all THR patients, results that agree with previous findings. ${ }^{3,4}$ However, given the same selection of patients, it is the negative attributable risk found in all subgroups of patients, except for young healthy patients, that could in principle indicate that THR surgery has a protective effect on mortality. However, a more reasonable explanation is probably that is is impossible to disentangle the effects of the surgery, patient comorbidity and selection for surgery on mortality. It is harder to explain why 
younger THR patients do not follow this pattern. In theory, these patients may suffer from more severe comorbidities or the physician may be less prone to record all comorbidities in younger THR patients than in controls from the general population, but this is hard to prove.

The strengths of our study include large numbers of subjects and the availability of nationwide population-based medical databases with a documented overall high to moderate data validity. ${ }^{28-30}$ Data were registered prospectively and independently of the objective of our study. Follow-up for mortality was complete, limiting the risk of selection and information bias. However, our study also has limitations. Assessment of comorbidity was based on routinely collected data from administrative registries which may be influenced by coding errors and misclassification of diagnoses. However, any misclassification would probably be independent of THR status. Furthermore, although our comorbidity data were limited to hospital discharge and specialist outpatient diagnoses, many of these diagnoses have previously been validated against medical records, and the accuracy was found to be more than $90 \% .{ }^{31}$ However, we had no information on the severity of medical conditions included in the Charlson comorbidity index, factors that may have introduced residual confounding into our analyses. Again, however, lack of severity of the comorbidities is most probably independent of THR status. Social status, drug use and physical activity before surgery and at follow-up may differ between THR patients and controls, and at the same time have an effect on mortality, introducing unmeasured confounding factors. Unfortunately, these data were not available in our dataset. Only the first primary THR, registered since the commencement of the Danish hip registry, was included. However, according to the Danish National Registry of Patients, $<1 \%$ of THR patients and a similar proportion of controls had primary THR before the Danish hip registry started. Finally, our study is observational, limiting the possibility of assessing causation in the association between THR and mortality.

In summary, THR was associated with lower short- and long-term mortality among patients with osteoarthritis than in controls from the general population. However, the association varied according to age, gender and comorbidity. Younger patients and patients without comorbidity before surgery have an increase in short-term relative mortality, although the absolute risk among these patients is small compared with older patients and those with greater comorbidity because of the lower background mortality. It is still possible that attention to the care of older patients and comorbid patients would provide a larger reduction in mortality. Nonetheless, the patients with the highest relative mortality risk, younger patients and those without comorbidity before surgery, may gain most from focused efforts to prevent potentially avoidable deaths.

\footnotetext{
The authors wish to thank the orthopaedic surgeons at all hospitals in Denmark for their co-operation regarding the Registry.

No benefits in any form have been received or will be received from a commercial party related directly or indirectly to the subject of this article.
}

\section{References}

1. Bjørnarå BT, Gudmundsen TE, Dahl $\mathrm{OE}$. Frequency and timing of clinical thromboembolism after major joint surgery. J Bone Joint Surg [Br] 2006;88-B:386-91.

2. Ethgen $\mathbf{0}$, Bruyère $\mathbf{0}$, Richy $\mathbf{F}$, Dardennes $\mathbf{C}$, Reginster JY. Health-related quality of life in total hip and total knee arthroplasty: a qualitative and systematic review of the literature. J Bone Joint Surg [Am] 2004;86-A:963-74.

3. Barrett J, Losina E, Baron JA, et al. Survival following total hip replacement. J Bone Joint Surg [Am]2005;87-A:1965-71.

4. Lie SA, Engesaeter LB, Havelin LI, Gjessing HK, Vollset SE. Mortality after total hip replacement: 0-10-year follow-up of 39,543 patients in the Norwegian Arthroplasty Register. Acta Orthop Scand 2000;71:19-27.

5. Mahomed NN, Barrett JA, Katz JN, et al. Rates and outcomes of primary and revision total hip replacement in the United States medicare population. J Bone Joint Surg [Am] 2003;85-A:27-32.

6. Cronin-Fenton DP, Nørgaard M, Jacobsen J, et al. Comorbidity and survival of Danish breast cancer patients from 1995 to 2005. Br J Cancer 2007;96:1462-8.

7. de Groot V, Beckerman H, Lankhorst GJ, Bouter LM. How to measure comorbidity: a critical review of available methods. J Clin Epidemio/ 2003;56:221-9.

8. Lund L, Borre M, Jacobsen J, Sørensen HT, Nørgaard M. Impact of comorbidity on survival of Danish prostate cancer patients, 1995-2006: a population-based cohort study. Urology 2008;72:1258-62

9. Blom A, Pattison G, Whitehouse S, Taylor A, Bannister G. Early death following primary total hip arthroplasty: 1,727 procedures with mechanical thrombo-prophylaxis. Acta Orthop 2006;77:347-50.

10. Gaston MS, Amin AK, Clayton RA, Brenkel IJ. Does a history of cardiac disease or hypertension increase mortality following primary elective total hip arthroplasty. Surgeon 2007:5:260-5.

11. Lie SA, Engesaeter LB, Havelin LI, Furnes O, Vollset SE. Early postoperative mortality after 67,548 total hip replacements: causes of death and thromboprophylaxis in 68 hospitals in Norway from 1987 to 1999. Acta Orthop Scand 2002;73:392-9.

12. Zhan C, Kaczmarek R, Loyo-Berrios N, Sangl J, Bright RA. Incidence and short-term outcomes of primary and revision hip replacement in the United States. J Bone Joint Surg [Am]2007;89-A:526-33.

13. Lübbeke A, Katz JN, Perneger TV, Hoffmeyer P. Primary and revision hip arthroplasty: 5-year outcomes and influence of age and comorbidity. J Rheumatol 2007;34:394-400.

14. Lucht U. The Danish Hip Arthroplasty Register. Acta Orthop Scand 2000;71:433-9.

15. World Health Organization. International Classification of Diseases. http:// www.who.int/classifications/icd/en. (date last accessed 15 December 2010).

16. Frank L. Epidemiology: when an entire country is a cohort. Science 2000;287:2398-9.

17. Charlson ME, Pompei P, Ales KL, MacKenzie CR. A new method of classifying prognostic comorbidity in longitudinal studies: development and validation. J Chronic Dis 1987:40:373-83.

18. Deyo RA, Cherkin DC, Ciol MA. Adapting a clinical comorbidity index for use with ICD9-CM administrative databases. J Clin Epidemiol 1992;45:613-19

19. Kleinbaum DG. Evaluating the proportional hazards assumption. In: Survival analysis: a self-learning text. Berlin: Springer-Verlag, 1996:129-69.

20. Hosmer DW Jr, Lemeshow S. Assessment of model adequacy. In: Applied survival analysis: regression modelling of time to event data. New York: John Wiley and Sons, 1999:196-240.

21. Lie SA, Pratt N, Ryan P, et al. Duration of the increase in early postoperative mortality after elective hip and knee replacement. J Bone Joint Surg [Am]2010;92-A:58-63.

22. Ramiah RD, Ashmore AM, Whitley E, Bannister GC. Ten-year life expectancy after primary total hip replacement. J Bone Joint Surg [Br]2007;89-B:1299-302.

23. Nilsson H, Stylianidis G, Haapamäki M, Nilsson E, Nordin P. Mortality after groin hernia surgery. Ann Surg 2007;245:656-60.

24. Meddings DR, Marion SA, Barer ML, et al. Mortality rates after cataract extraction. Epidemiology 1999;10:288-93.

25. Parvizi J, Johnson BG, Rowland C, Ereth MH, Lewallen DG. Thirty-day mortality after elective total hip arthroplasty. J Bone Joint Surg [Am]2001;83-A:1524-8.

26. Pedersen AB, Johnsen SP, Overgaard S, et al. Total hip arthroplasty in Denmark: incidence of primary operations and revisions 1996-2002 and estimated future demands. Acta Orthop 2005;76:182-9

27. Mahomed NN, Liang MH, Cook EF, et al. The importance of patient expectations in predicting functional outcomes after total joint arthroplasty. J Rheumatol 2002;29:1273-9.

28. Madsen M, Davidsen M, Rasmussen S, Abildstrom SZ, Osler M. The validity of the diagnosis of acute myocardial infarction in routine statistics: a comparison of mortality and hospital discharge data with the Danish MONICA registry. J Clin Epidemio/ 2003;56:124-30.

29. Nickelsen TN. Danish validity and coverage in the Danish National Health Registry: a literature review. Ugeskr Laeger 2001;164:33-7 (in Danish).

30. Pedersen A, Johnsen S, Overgaard S, et al. Registration in the Danish Hip Arthroplasty Registry: completeness of total hip arthroplasties and positive prediction value of registered diagnosis and postoperative complications. Acta Orthop Scand 2004;75:434-41.

31. Thygesen SK, Christiansen CF, Lash TL, Christensen S, Sørensen HT. The predictive value of ICD-10 diagnoses in population-based hospital registries used to assess Charlson Comorbidity Index. Pharmacoepidemiology and Drug Safety 2009;18 (Suppl):189 (abstract) 